\title{
SIMULASI PENGARUH VARIASI KECEPATAN INLET TERHADAP PERSENTASE PEMISAHAN PARTIKEL PADA CYCLONE SEPARATOR DENGAN MENGGUNAKAN CFD
}

\author{
A.Husairy ${ }^{1}$ dan Benny D Leonanda ${ }^{2}$
}

\begin{abstract}
ABSTRAK
Pada tulisan ini akan dibahas pengaruh kecepatan dan dimensi terhadap persentase pemisahan partikel cyclone separator dengan menggunakan CFD. Persamaan yang digunakan dalam CFD adalah persamaan kepsilon RNG. Variasi kecepatan 7, 10, 15, 20, dan 30m/s dilakukan untuk mengetahui pengaruhnya terhadap persentase pemisahan partikel. Variasi lebar inlet 0,2 dan $0.25 \mathrm{~m}$ serta diameter outlet 0.4 dan $0.5 \mathrm{~m}$ juga dilakukan untuk mengetahui pengaruhnya terhadap cyclone separator. Persentase pemisahan partikel didapat dengan simulasi Particle Track. Dimana pada penelitian didapat jumlah partikel yang Escaped ataupun Trapped. Escaped adalah jumlah partikel yang ikut keluar bersama udara bersih, sedangkan Trapped adalah partikel yang telah disisihkan dari udara bersih dan masuk kedalam chopper. Pada simulasi ini juga didapat kontur tekanan dan kecepatan dari cyclone separator tersebut. Dari hasil simulasi didapatkan bahwa variasi kecepatan cukup berpengaruh terhadap persentase pemisahan partikel, dimana semakin tinggi kecepatan inlet maka persentase partikel yang escaped semakin sedikit dan yang trapped semakin bertambah. Dari 4 tipe cyclone separator yang disimulasikan, cyclone separator dengan diameter outlet $0.4 \mathrm{~m}$ dan lebar inlet $0.25 \mathrm{~m}$ menghasilkan persentase pemisahan yang paling tinggi, untuk kecepatan $20 \mathrm{~m} / \mathrm{s}$, hanya $4.54 \%$ partikel yang keluar bersama udara bersih. Tapi cyclone separator ini menghasilkan tekanan yang lebih tinggi dibandingkan cyclone separator tipe lainnya.
\end{abstract}

Kata kunci : cyclone separator, kecepatan, tekanan, persentase pemisahan partikel

\section{PENDAHULUAN}

\subsection{Latar Belakang}

Pencemaran udara yang berupa partikulat dapat diatasi dengan alat-alat pengontrol udara seperti cyclone separator. Prinsip alat ini adalah memisahkan partikel padat dan gas dengan memanfaatkan gaya sentrifugal dan gaya gravitasi didalam cyclone separator. Didalam cyclone tersebut terjadi vortex, yang mengakibatkan partikulat dan gas akan terpisah, dimana partikulat yang bermassa jenis besar akan jatuh kebawah dan udara yang bermassa jenis kecil akan naik keatas. Efisiensi pemisahan partikel bergantung pada diameter partikel, massa jenis partikel, dan dimensi cyclone separator. Kecepatan masuk inlet juga cukup mempengaruhi persentase pemisahan partikel.

Computation Fluid Dynamic (CFD) adalah suatu program yang dapat menganalisis suatu sistem, dalam CFD ini dapat terlihat kontur keadaan seperti kecepatan ataupun tekanan. Dengan menggunakan CFD ini juga dapat mensimulasikan aliran partikel dalam cyclone, dimana dapat dilihat berapa banyak partikel yang terperangkap ataupun yang keluar dari cyclone. Dengan

\footnotetext{
${ }^{1}$ Mahasiswa Jurusan Teknik mesin Fakultas Teknik Universitas Andalas, Husai_ii@yahoo.com

${ }^{2}$ Staf Pengajar Jurusan Teknik Mesin Fakultas Teknik Universitas Andalas, benny@ft.unand.ac.id
} 
simulasi tersebut dapat diketahui pengaruh kecepatan inlet terhadap persentase pemisahan partikel, juga pengaruh dimensi cyclone separator terhadap persentase pemisahan partikel.

\subsection{Tujuan dan Manfaat}

Penelitian ini dilakukan dengan tujuan untuk Melihat karakteristik cyclone dengan berbagai variasi kecepatan inlet dengan dimensi cyclone yang berbeda. Juga untuk mengetahui pengaruh kecepatan inlet terhadap persentase pemisahan partikel pada cyclone separator

\section{TINJAUAN PUSTAKA}

Cyclone Separator adalah suatu peralatan mekanis yang sederhana, merupakan jenis dari pengendali kering (Dry Scrubber), biasanya digunakan untuk menyisihkan partikel dengan ukuran relatif besar dari suatu aliran gas. Cyclone memiliki bentuk yang khas dan mudah dikenal dan dapat ditemukan pada hampir setiap industri. Cyclone dapat ditempatkan di atap dari suatu instalasi atau disamping bangunan. Diameter cyclone bervariasi dan digunakan sebagai alat kontrol polusi udara. Alat ini menggunakan gaya sentrifugal sebagai driving force pemisahan debu dari gas yang akan dihasilkan kegiatan suatu industri. Alat ini memiliki biaya instalasi dan operasi yang rendah, serta memiliki dimensi yang relatif kecil untuk mendukung efisiensinya. Keuntungan tersebut membuat cyclone banyak digunakan industri pertambangan untuk mengumpulkan partikel debu yang akan menimbulkan pencemaran udara

Dalam aplikasi dunia industri, cyclone sering digunakan sebagai precleaner untuk alat kontrol polusi udara. Cyclone lebih efisien digunakan untuk memisahkan partikulat daripada settling chamber, tetapi tidak lebih efisien bila dibandingkan dengan wet scrubber, baghouses atau electric precipitator. Cyclone sering digambarkan sebagai peralatan dengan efisiensi rendah. Namun dalam perkembangannya, tercatat, cyclone mampu menghasilkan efisiensi 98\% bahkan lebih untuk partikel yang lebih besar dari 5 microns (Cooper, et al., 1986). Efisiensi lebih dari 98\% juga tercatat pada cyclone untuk partikel yang diameternya lebih dari 346 microns (Funk, P.A., et al., 2000).

\subsection{Gambaran Umum Cyclone Separator}

Cyclone dapat didesain atau dibuat dengan berbagai cara. Desain yang umum adalah cyclone dengan inlet tangensial. Jenis cyclone ini mempunyai empat bagian, yaitu inlet, body, sistem pembuangan debu, dan outlet.

1. Inlet merupakan bagian dimana gas dan partikulat masuk. Jalannya gas dan partikulat ini dalam arah lurus dan kemudian berubah menjadi gerakan berputar pada dinding. Inlet berada pada bagian pinggir dari cyclone. Hal ini bertujuan agar agar terjadi vortex dalam cyclone.

2. Body. Efisiensi pemisahan partikel dari cyclone tergantung dari ukuran atau dimensi cyclone. Pembuatan cyclone ditentukan oleh debit gas yang memasuki cyclone dan efisiensi yang diinginkan. Dimensi yang paling penting adalah diameter partikel. Berikut adalah dimensi standar cyclone separator

3. Sistem Pembuangan Debu. Partikulat yang terkumpul harus dibuang dari cyclone atau akan menghambat kinerja cyclone. Terdapat sejumlah metoda yang dapat digunakan untuk membuang partikel terkumpul baik secara periodik ataupun secara kontinu. Manual slide gate pada bagian bawah cone dapat digunakan untuk pembuangan debu secara periodik, sedangkan rotary valve dapat digunakan untuk pembuangan debu secara kontinu.

4. Outlet merupakan bagian dimana udara bersih keluar. Udara bersih ini didapat dari pemisahan udara dan partikel didalam siklon. Umumnya, pada outlet ini juga terdapat 
partikel yang keluar. Hal ini disebabkan karena efisiensi pemisahan partikel yang hanya sekitar $90 \%$.

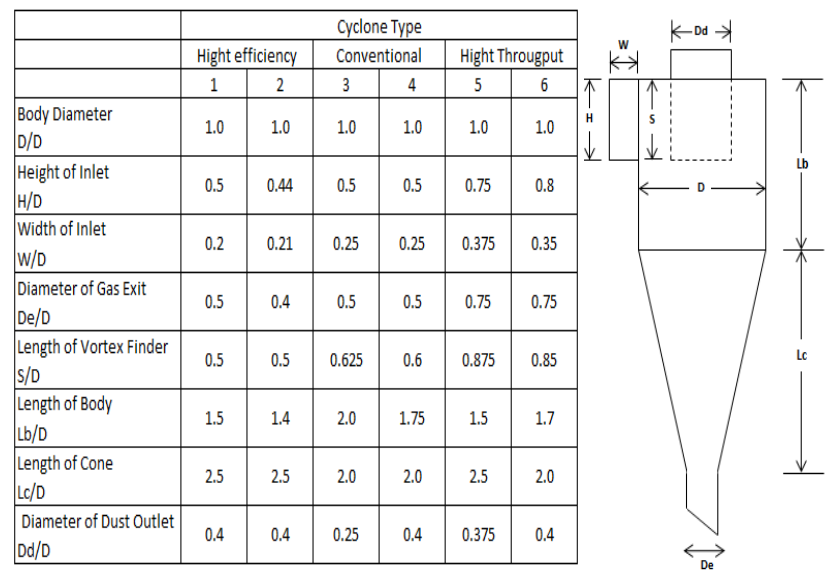

Source : columns (1) and (5) from Stairmand 1951, columns (2) and (6) from Swift, column (3) from Lapple 1951

Gambar 1. Dimensi standar cyclone separator

\subsection{Mekanisme Cyclone}

Pada prinsipnya, terdapat dua gaya mekanisme yang mempengaruhi pengumpulan debu, yaitu gaya sentrifugal dan gaya gravitasi. Kumpulan gas dan partikel ditekan ke bawah secara spiral karena bentuk dari cyclone. Gaya sentrifugal dan gaya inersia menyebabkan partikel terlempar ke arah luar, membentur dinding dan kemudian bergerak turun ke dasar cyclone. Gerakan spiral aliran gas berkembang sejalan dengan masuknya gas. Gas bergerak sepanjang dinding cyclone, berputar beberapa kali secara spiral dan bergerak kebawah, seperti gerakan dari topan tornado. Saat gas mencapai dasar cyclone, gerakan akan berputar kearah berlawanan dan menuju ke pusat tabung lalu bergerak keatas.

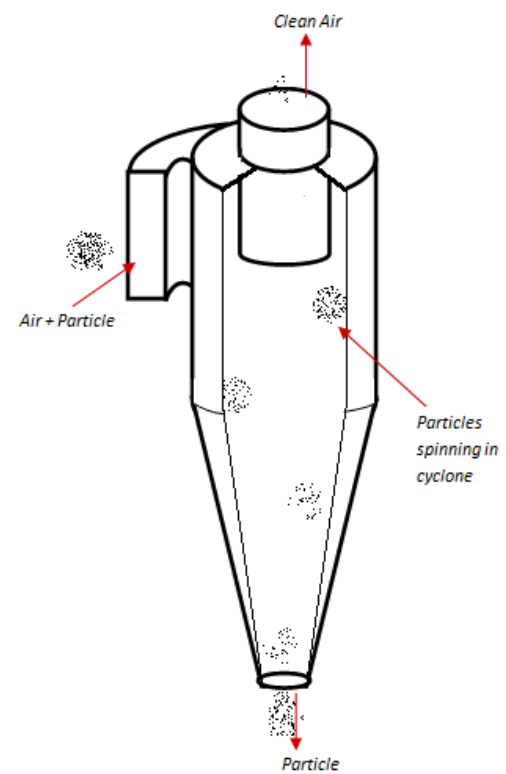

Gambar 2. Mekanisme cyclone 
Pada bagian silinder dari cyclone, partikulat akan terbawa oleh dinding, dengan kata lain partikel bergerak kearah dinding dengan gerakan yang dilakukan oleh gaya sentrifugal. Pada bagian cone, bentuk menyempit memberikan kesempatan terjadinya kecepatan rotasi yang cukup untuk mempertahankan gerakan partikel pada dinding. Hal ini dapat mencegah terjadinya gerakan partikel kembali memasuki aliran gas. Partikel yang jatuh kedasar akan terkumpul dan dapat dibersihkan secara periodik.

\section{METODOLOGI PENELITIAN}

Penelitian dilakukan dengan menggunakan software CFD dengan persamaan k-epsilon RNG. Model k-epsilon merupakan model turbulensi yang cukup lengkap dengan 2 persamaan yang memungkinkan kecepatan turbulen dan skala panjang ditentukan secara independen. Kestabilan, ekonomis (dari sisi komputasi), dan akurasi yang memadai untuk berbagai jenis aliran turbulen membuat model k-epsilon sering digunakan pada simulasi aliran fluida dan pepindahan panas. kepsilon RNG digunakan karena efek putaran pada turbulensi juga terdapat pada model RNG sehingga meningkatkan akurasi untuk aliran yang berputar. Pada simulasi ini dianggap tidak terjadi slip pada partikel.

Cyclone separator yang disimulasikan adalah cyclone tipe high efficiency, dengan dimensi yang ada, divariasikan menjadi 4 tipe dengan lebar inlet dan diameter outlet yang berbeda. Berikut dimensi cyclone tersebut :

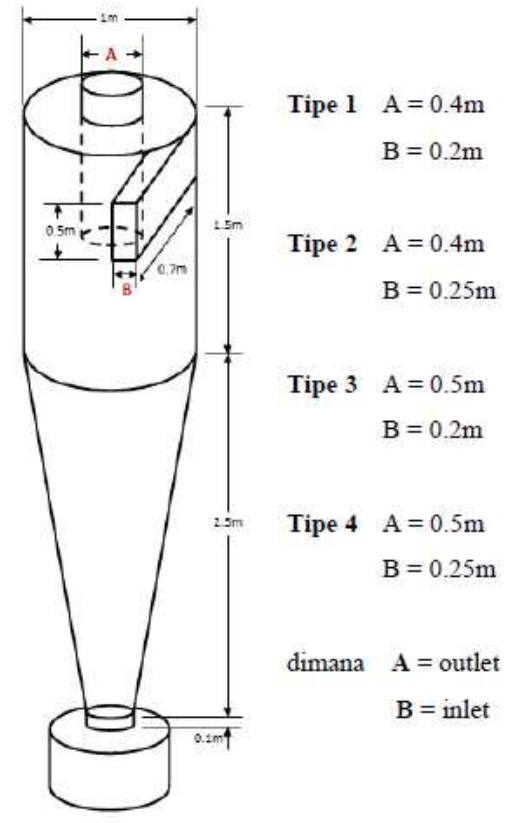

Gambar 3. Variasi dimensi cyclone separator

Pengujian ini dilakukan dengan kecepatan 7, 10, 15, 20, dan $30 \mathrm{~m} / \mathrm{s}$. Berat jenis udara $1.225 \mathrm{~kg} / \mathrm{m} 3$ sedangkan berat jenis partikel $2100 \mathrm{~kg} / \mathrm{m} 3$. Ukuran partikel adalah $5 \mathrm{e}^{-6}-300 \mathrm{e}^{-6} \mu \mathrm{m}$, dengan flow rate $0.001 \mathrm{~kg} / \mathrm{s}$. Pada simulasi ini didapatkan kontur tekanan dan kecepatan untuk tiap-tiap dimensi cyclone separator. Dan untuk persentase pemisahan partikel, didapatkan melalui simulasi Particle Track. Pada simulasi ini didapat partikel Escaped yaitu partikel yang bebas keluar bersama udara bersih, dan Trapped yaitu partikel yang tersisihkan dari udara dan masuk kedalam chopper. 


\section{HASIL DAN PEMBAHASAN}

Dari hasil simulasi CFD diperoleh kontur tekanan dan kecepatan yang berbeda untuk tiap dimensi cyclone separator. Pada simulasi ini, bentuk kontur tekanan dan kecepatan tersebut relatif sama untuk kecepatan yang berbeda, yang membedakan hanya nilai maksimum dan minimum dari kontur tersebut, dimana range tekanan dan kecepatannya berbeda. Cyclone tipe 2 menghasilkan tekanan yang lebih tinggi dibanding cyclone tipe lain. Begitu juga untuk kecepatan. Berikut gambar kontur tekanan dan kecepatan dari cyclone separator secara berurutan dari tipe 1 hingga tipe 4:

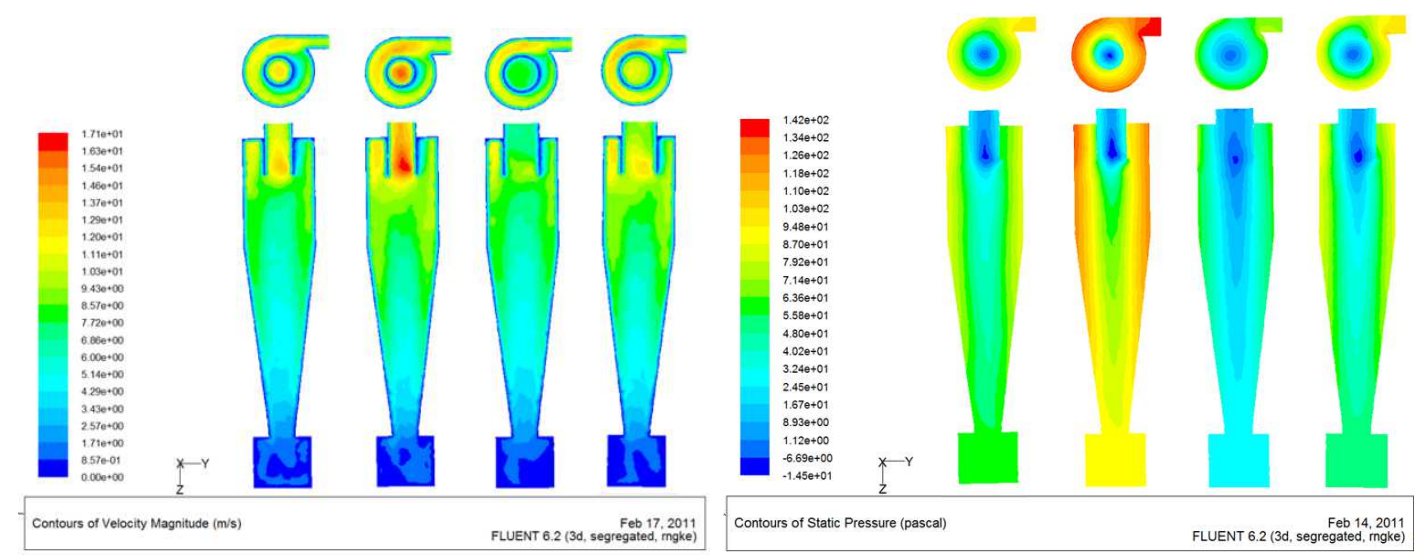

Gambar 4. Kontur tekanan dan kecepatan untuk kecepatan masuk $7 \mathrm{~m} / \mathrm{s}$

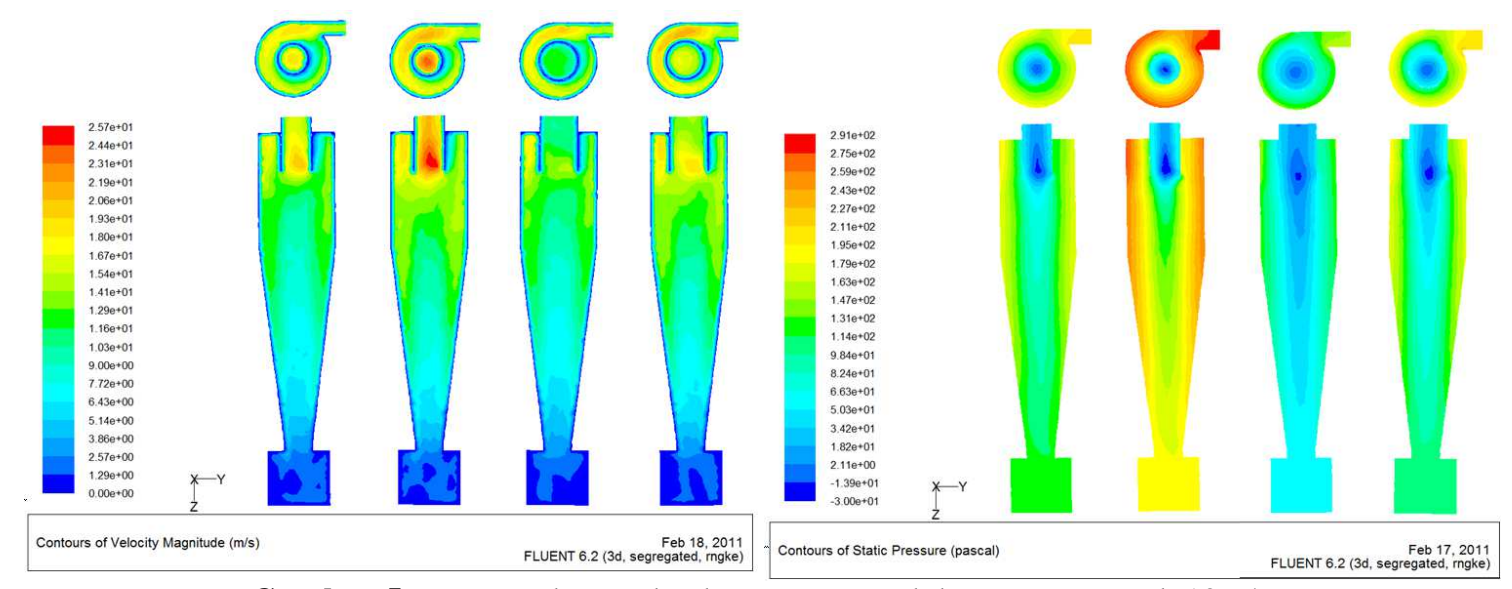

Gambar 5. Kontur tekanan dan kecepatan untuk kecepatan masuk 10m/s

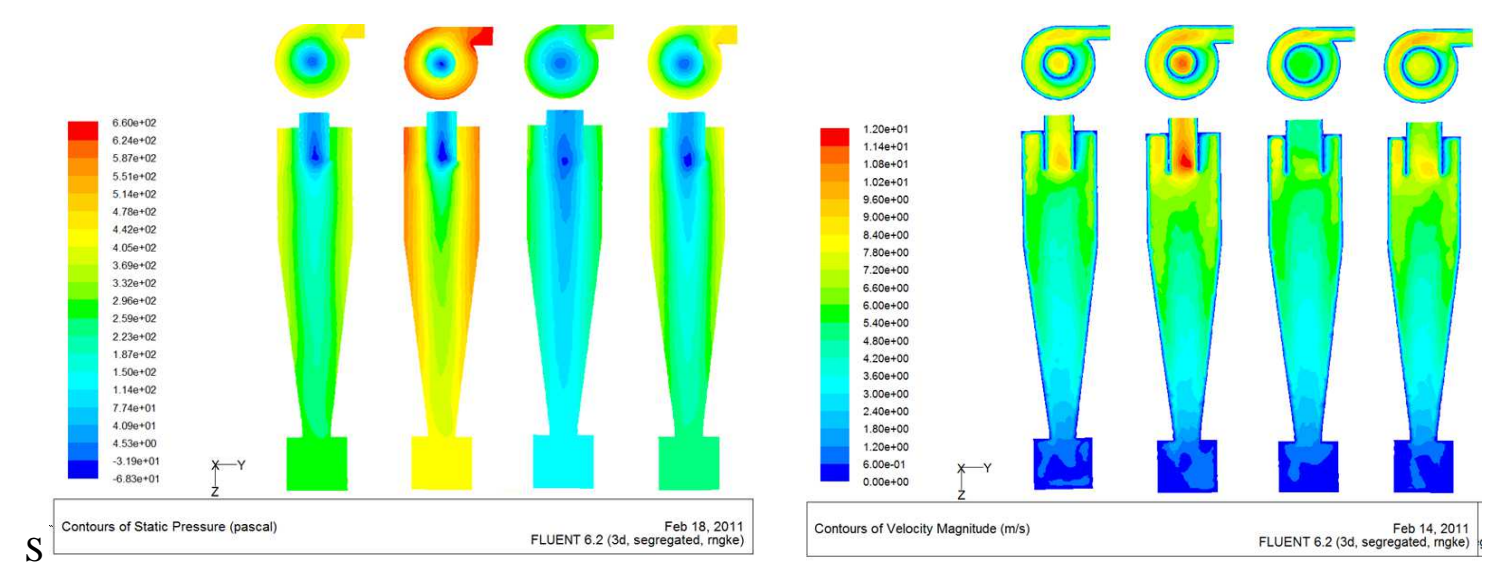

16 | JURNAL REKAYASA SIPIL 
Gambar 6. Kontur tekanan dan kecepatan untuk kecepatan masuk 15m/s

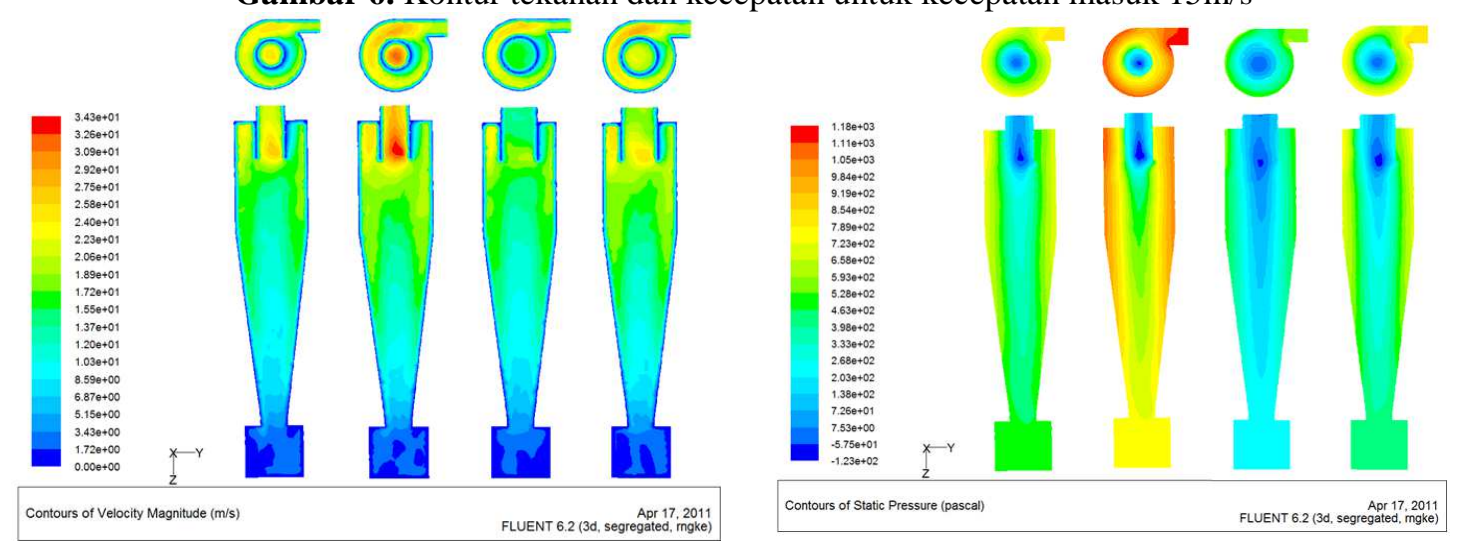

Gambar 7. Kontur tekanan dan kecepatan untuk kecepatan masuk 20m/s
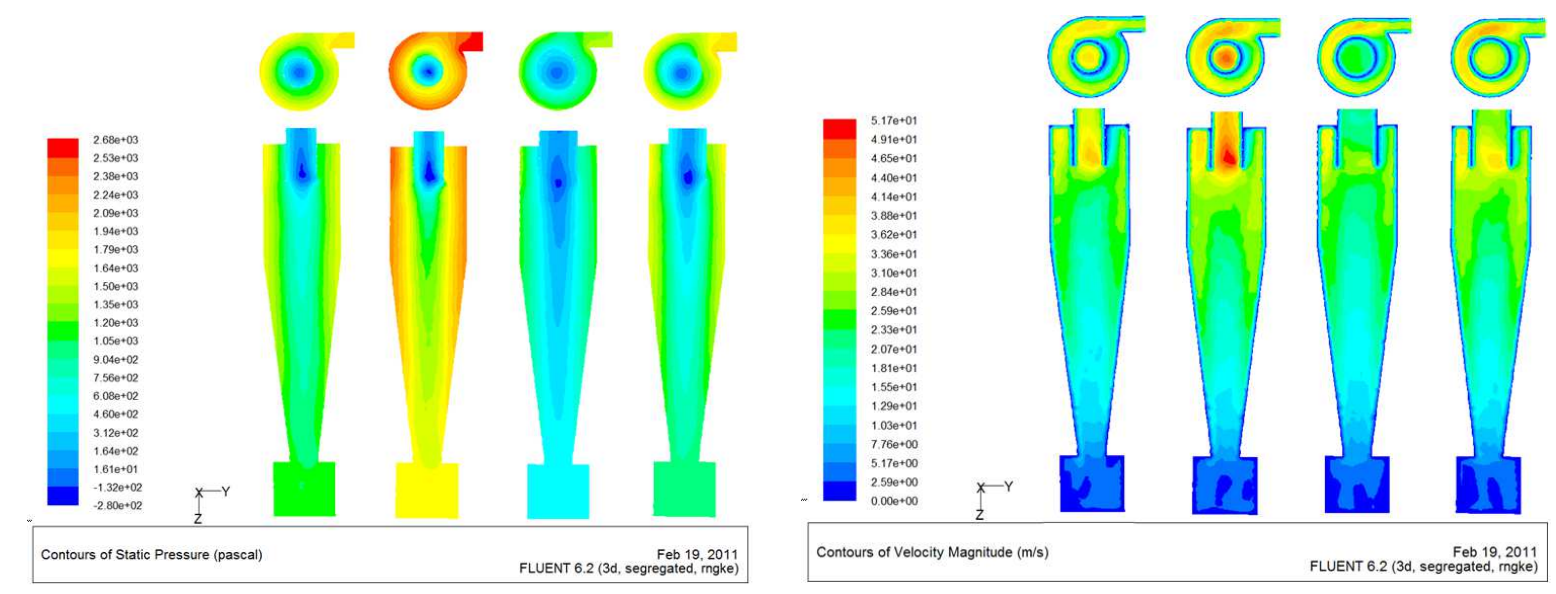

Gambar 8. Kontur tekanan dan kecepatan untuk kecepatan masuk 30m/s

\subsection{Kontur Tekanan dan Kecepatan}

Dari simulasi didapatkan kontur tekanan yang berbeda untuk masing-masing dimensi cyclone. Dari kontur tersebut terlihat bahwa cyclone tipe 2 dengan diameter outlet $0.4 \mathrm{~m}$ menghasilkan tekanan yang lebih tinggi dibandingkan dengan ketiga tipe lain. Dari kontur tekanan tersebut juga dapat dilihat bahwa cyclone dengan diameter outlet $0.5 \mathrm{~m}$ menghasilkan kontur tekanan yang lebih rendah dibanding diameter outlet $0.4 \mathrm{~m}$.

Lebar inlet juga mempengaruhi kontur tekanan pada cyclone. Untuk diameter outlet yang sama, cyclone dengan lebar inlet $0.25 \mathrm{~m}$ menghasilkan kontur tekanan yang lebih tinggi daripada cyclone dengan lebar inlet $0.2 \mathrm{~m}$. sebagai pembanding dapat dilihat pada cyclone tipe 1 dan 2 , juga cyclone tipe 3 dan 4, dimana kontur tekanan cyclone tipe 2 dengan lebar inlet $0.25 \mathrm{~m}$ lebih tinggi daripada kontur tekanan cyclone tipe $10.2 \mathrm{~m}$. begitu juga dengan cyclone tipe 3 dan 4 . Penyebabnya adalah jumlah udara yang masuk dalam cyclone dengan lebar inlet $0.25 \mathrm{~m}$ lebih banyak dari cyclone dengan lebar inlet $0.2 \mathrm{~m}$.

Tekanan maksimum pada cyclone terjadi pada daerah inlet, dimana pada daerah ini partikel dan dan udara saling bertumbukan. Sedangkan tekanan minimum berada pada daerah tengah outlet. Berikut tabel tekanan maksimum dan minimum dari cyclone separator. 
Sedangkan untuk profil kecepatan didapatkan hasil yang sama, yaitu cyclone dengan lebar inlet $0.25 \mathrm{~m}$ menghasilkan kecepatan yang lebih tinggi daripada cyclone dengan lebar inlet $0.2 \mathrm{~m}$. Kecepatan maksimum terdapat pada bagian tengah outlet dimana pada bagian tersebut tekanan berada pada batas minimumnya.

Tabel 1. Tekanan maksimum dan minimum cyclone separator

\begin{tabular}{|c|c|c|c|c|}
\hline \multirow{2}{*}{$\begin{array}{c}\text { Kecepatan } \\
(\mathrm{m} / \mathrm{s})\end{array}$} & \multicolumn{4}{|c|}{ Tekanan Maksimum (Pascal) } \\
\cline { 2 - 5 } & tipe 1 & tipe 2 & tipe 3 & tipe 4 \\
\hline 7 & 99.95 & 141.67 & 75.9 & 105.14 \\
10 & 205.46 & 291.09 & 156.21 & 21.05 \\
15 & 466.81 & 659.93 & 354.28 & 489.89 \\
20 & 834.36 & 1179 & 633.46 & 875.84 \\
30 & 1891.58 & 2680.81 & 1437.59 & 1983.93 \\
\hline \hline Kecepatan & \multicolumn{4}{|c|}{ Tekanan Minimum (Pascal) } \\
\cline { 2 - 5 }$(\mathrm{m} / \mathrm{s})$ & tipe 1 & tipe 2 & tipe 3 & tipe 4 \\
\hline 7 & -9.47 & -14.47 & -8.46 & -12.34 \\
10 & -19.74 & -29.93 & -17.66 & -26.21 \\
15 & -45.83 & -68.3 & -40.83 & -60.35 \\
20 & -82.63 & -122.63 & -73.91 & -109.24 \\
30 & -189.12 & -280 & -170.77 & -251.72 \\
\hline
\end{tabular}

\begin{tabular}{|c|c|c|c|c|}
\hline \multirow{2}{*}{$\begin{array}{c}\text { eecepatan } \\
(\mathrm{m} / \mathrm{s})\end{array}$} & \multicolumn{4}{|c|}{ Kecepatan Maksimum (m/s) } \\
\cline { 2 - 5 } & tipe 1 & tipe 2 & tipe 3 & tipe 4 \\
\hline 7 & 9.37 & 11.95 & 9.41 & 9.97 \\
10 & 13.41 & 17.1 & 13.48 & 14.28 \\
15 & 20.17 & 25.72 & 20.26 & 21.49 \\
20 & 26.94 & 34.35 & 27.07 & 28.71 \\
30 & 40.52 & 51.71 & 40.71 & 43.19 \\
\hline
\end{tabular}

Gambar 9. Kecepatan maksimum dari cyclone separator

\subsection{Persentase Pemisahan Partikel}

Persentase pemisahan partikel didapat dari simulasi Particle Track. Simulasi ini menghasilkan partikel Escaped dan Trapped. Persentase partikel dihitung dan dibandingkan jumlahnya terhadap jumlah partikel semula.

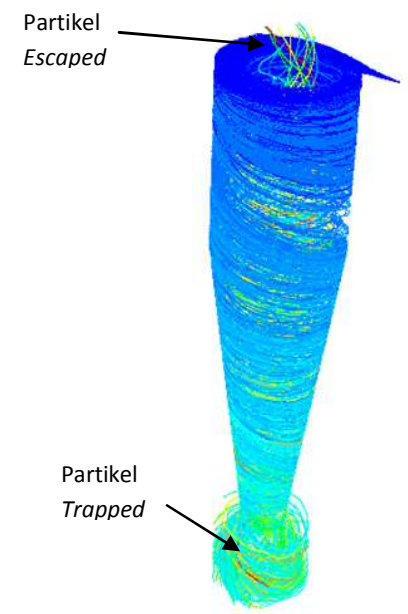


Gambar 10. Simulasi particle track

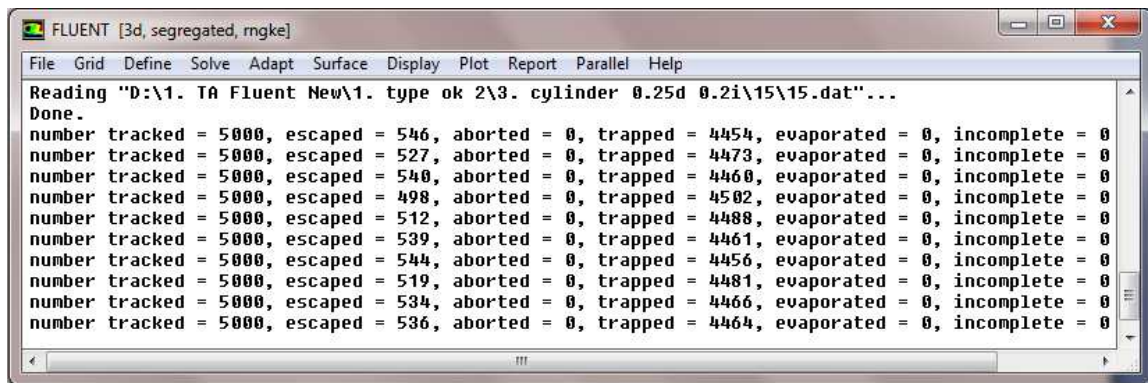

Gambar 11. Contoh Hasil simulasi partikel escaped dan trapped

Dari perbandingan didapatkan persentase partikel sebagai berikut :

Tabel 2. Persentase Partikel Escaped

\begin{tabular}{|c|c|c|c|c|}
\hline $\begin{array}{c}\text { Kecepatan } \\
(\mathrm{m} / \mathrm{s})\end{array}$ & $\begin{array}{c}\text { Tipe 1 } \\
(\%)\end{array}$ & $\begin{array}{c}\text { Tipe 2 } \\
(\%)\end{array}$ & $\begin{array}{c}\text { Tipe 3 } \\
(\%)\end{array}$ & $\begin{array}{c}\text { Tipe 4 } \\
(\%)\end{array}$ \\
\hline 7 & 8.31 & 10.71 & 15.83 & 10.61 \\
\hline 10 & 6.66 & 8.41 & 13.65 & 8.98 \\
\hline 15 & 6.34 & 6.00 & 10.59 & 7.14 \\
\hline 20 & 5.39 & 4.54 & 8.61 & 6.15 \\
\hline 30 & 3.67 & 2.39 & 6.56 & 4.69 \\
\hline
\end{tabular}

Tabel 3. Persentase Partikel Trapped

\begin{tabular}{|c|c|c|c|c|}
\hline $\begin{array}{c}\text { Kecepatan } \\
(\mathbf{m} / \mathbf{s})\end{array}$ & $\begin{array}{c}\text { Tipe 1 } \\
(\%)\end{array}$ & $\begin{array}{c}\text { Tipe 2 } \\
(\%)\end{array}$ & $\begin{array}{c}\text { Tipe 3 } \\
(\%)\end{array}$ & $\begin{array}{c}\text { Tipe 4 } \\
(\%)\end{array}$ \\
\hline 7 & 91.69 & 89.29 & 84.16 & 89.39 \\
\hline 10 & 93.34 & 91.57 & 86.35 & 92.49 \\
\hline 15 & 93.66 & 94.00 & 89.41 & 92.86 \\
\hline 20 & 94.61 & 95.46 & 91.39 & 93.85 \\
\hline 30 & 96.33 & 97.61 & 93.44 & 95.31 \\
\hline
\end{tabular}

dari tabel tersebut didapat grafik :

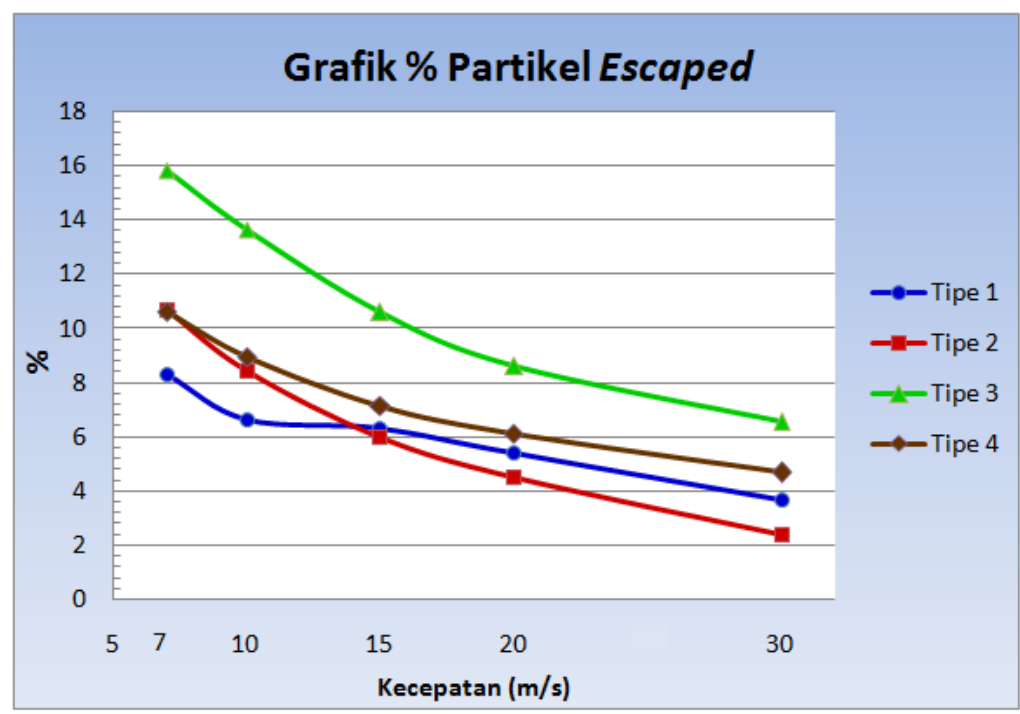


Gambar 12. Grafik persentase partikel Escaped

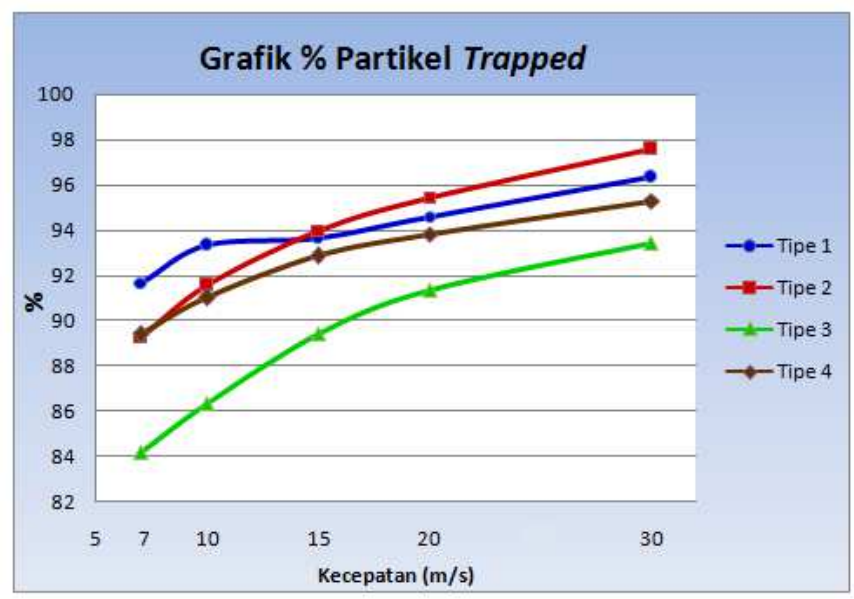

Gambar 13. Grafik persentase partikel Trapped

\subsection{Pengaruh Kecepatan Inlet}

Efisiensi cyclone separator tergantung dari jumlah partikel yang trapped dan yang escaped. Semakin sedikit partikel yang escaped, berarti semakin banyak partikel yang trapped dan efisiensi partikel tersebut semakin baik. Dari grafik untuk berbagai tipe terlihat bahwa kenaikan kecepatan inlet mempengaruhi persentase pemisahan partikel, dimana partikel escaped semakin berkurang dan partikel trapped semakin meningkat, walaupun kenaikan tersebut tidak signifikan.

Partikel yang akan dipisahkan dari udara bersih haruslah tetap mempunyai kecepatan yang cukup agar tetap berada didinding cyclone. Pada daerah dinding cyclone terjadi vortex paksa. Gaya sentrifugal dan gravitasi akan menyebabkan partikel tersebut akan berputar di dinding silinder cyclone hingga kedaerah cone kemudian masuk ke chopper. Daerah cone dibuat agar terjadi kecepatan rotasi yang cukup dari partikel untuk mempertahankan gerakan partikel pada dinding. Semakin cepat masukan inlet maka kesempatan partikel untuk tetap berada didinding cyclone semakin besar dan persentase pemisahan partikel pun semakin tinggi.

\subsection{Pengaruh Diameter Outlet}

Diameter outlet pada simulasi ini juga mempengaruhi persentase pemisahan partikel, dimana didapat cyclone dengan diameter outlet $0.4 \mathrm{~m}$ yaitu tipe 1 dan 2 menghasilkan efisiensi yang lebih tinggi daripada cyclone tipe 3 dan 4 dengan diameter outlet $0.5 \mathrm{~m}$. Hal ini terjadi karena kesempatan partikel untuk keluar menuju outlet menjadi lebih kecil karena diameter outlet tersebut lebih kecil. Pada daerah bagian tengah cyclone terjadi vortex bebas sehingga udara dan partikel yang tidak tersisihkan menuju outlet lalu ke lingkungan. Walaupun persentase pemisahan partikel tersebut tinggi, namun tekanan dalam cyclone yang didapat juga tinggi. Hal ini tidak tentu diinginkan karena akan menghasilkan pressure drop yang tinggi juga.

\subsection{Pengaruh Lebar Inlet}

Pada simulasi ini lebar inlet yang diuji hanya 0.2 dan $0.25 \mathrm{~m}$. Simulasi ini menghasilkan cyclone tipe 2 dan 4 dengan lebar inlet $0.25 \mathrm{~m}$ mempunyai persentase pemisahan partikel yang lebih baik dari cyclone tipe 1 dan 3 dengan diameter $0.2 \mathrm{~m}$ untuk diameter outlet yang sama. Dengan kata lain, cyclone tipe 2 lebih baik dari cyclone tipe 1 dan cyclone tipe 4 lebih baik dari cyclone tipe 3 . 
Penyebabnya adalah karena flow rate partikel sama yaitu $0.001 \mathrm{~kg} / \mathrm{s}$ sedangkan massa udara yang masuk dengan lebar inlet 0.25 lebih banyak daripada $0.2 \mathrm{~m}$.

\section{KESIMPULAN DAN SARAN}

\subsection{Kesimpulan}

Berdasarkan hasil simulasi dan pembahasan, dapat diambil kesimpulan :

1. Outlet diameter $0.4 \mathrm{~m}$ menghasilkan persentase pemisahan partikel yang lebih tinggi dari diameter outlet $0.5 \mathrm{~m}$, namun menghasilkan kontur tekanan yang lebih tinggi pula, hal ini dapat dibandingkan pada cyclone tipe 1 dengan tipe 3, atau tipe 2 dengan tipe 4 .

2. Lebar inlet juga mempengaruhi persentase pemisahan partikel dimana cyclone dengan lebar inlet $0.25 \mathrm{~m}$ menghasilkan persentase pemisahan paartikel yang lebih tinggi dari lebar inlet $0.2 \mathrm{~m}$, dapat dibandingkan pada cyclone tipe 1 dengan tipe 2, atau tipe 3 dengan tipe 4

3. Persentase pemisahan partikel meningkat seiring kenaikan kecepatan, yaitu persentase partikel escaped akan menurun dan persentase partikel trapped akan meningkat.

\subsection{Saran}

Berdasarkan penelitian yang telah dilakukan, beberapa hal yang dapat disarankan adalah:

1. Perlu dilakukan meshing yang lebih baik agar hasil yang didapat lebih akurat

2. Menggunakan persamaan lain seperti Spart Allmaras atau Reynold Stress sebagai pembanding

\section{DAFTAR KEPUSTAKAAN}

Bapedal, AUSAID, Pengendalian Pencemaran Udara, Jurusan Teknik Lingkungan, UNAND.

[Cooper, C.D. and Alley, F.C, 1986. Air Pollution Control, USA

Funk, P.A, Ed Hughs, S. , Holt, G.A, 2000. Entrance Velocity Optimization for Modified Dust Cyclones, The Journal of Cotton Science 4: 178-182

Gambit Tutorial Guide (2000), Fluent incorporated.

Tuakia, Firman, 2008. Dasar-dasar Menggunakan CFD Fluent, Informatika, Bandung.

White, F.M. 1998. Mekanika Fluida, jilid I, Edisi Kedua, Erlangga, Jakarta 